\title{
Chapter 13 \\ Use of Nanostructured Coating to Improve Heat Exchanger Efficiency
}

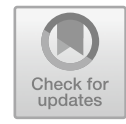

\author{
Antonino Bonanno, Mariarosa Raimondo and Michele Pinelli
}

\begin{abstract}
This work investigates the potential of surface nano-coatings on the heat transfer surface of heat exchangers, in order to improve their overall efficiency in terms of pressure drop and heat power exchanged. The work started from the consideration that, due to the increasingly strict international standards, the machines will be provided with optimized engines with new and improved devices to reduce the exhaust emissions (liquid cooled EGR valves, new catalytic converters and DPF systems) which reduce inevitably the space in the engine compartment. In this paper it is studied the feasibility of the coating processes and the adaptability of deposition techniques to the industrial production process of cross flow heat exchanger fins. The innovative exchanger performance, investigated using dedicated test rigs, shows that the results are influenced by the coating technology.
\end{abstract}

\subsection{Scientific and Industrial Motivations}

Heat exchanger efficiency is one of the main concerns in trying to improve the overall efficiency of mobile off-road machines and industrial plants. Compact radiators play a fundamental role in temperature control of internal combustion engines (ICE) and hybrid drivelines. An improvement of this component could affect the global efficiency of the machine. Typically, the problem is studied from a geometrical point of view, using different production lines to make fins geometries dedicated to improve the heat exchange or to reduce the pressure drop. Heat exchanger optimization is needed to obtain smaller, lighter, but at the same time more efficient radiators.

\footnotetext{
A. Bonanno $(\varangle)$

CNR-IMAMOTER, Istituto per le Macchine Agricole e Movimento Terra, Ferrara, Italy

e-mail: a.bonanno@imamoter.cnr.it
}

M. Raimondo

CNR-ISTEC, Istituto di Scienza e Tecnologia dei Materiali Ceramici, Faenza, Ravenna, Italy

M. Pinelli

Università di Ferrara, Ferrara, Italy

(C) The Author(s) 2019

T. Tolio et al. (eds.), Factories of the Future,

https://doi.org/10.1007/978-3-319-94358-9_13 
In this paper, we propose to focus the attention on the possibility to change the performance not only via geometrical modifications, but also considering new production processes to functionalize the heat exchanger surfaces, thus enabling to customize the performance based on the specific requests. Indeed, the laminar layer height, which influences the ability to exchange heat and the pressure drop could be modified by changing the surface functionalization while keeping the same geometry. Therefore, the use of functionalized coating could improve the heat exchanger performance, giving the possibility to develop new product families able to satisfy the market requests, especially for tailored (high value-high technological content) products. The use of functionalized coating (superhydrophobic and oleophobic) in heat exchanger has not been tested until now. Recently some studies dedicated to the applicability of nanostructured coating on hydraulic piston pumps have been presented [1]. The structure of a nanoscale surfaces enables to modify its wetting and the fluid interaction. Thus, it is possible to reach high levels of repulsion against water (super-hydrophobicity) or oils/alcohols (oleophobicity).

This work studies the potential of a novel nanostructured coating, featuring superhydrophobic and oleophobic behaviour, in providing better performance to the heat exchanger for fixed and mobile circuit. Different production technologies were investigated with the aim to further develop the currently most easily adaptable methodology, i.e. hot brazing.

Moreover, a software tool was developed to optimize the heat exchanger geometry performance, thus ensuring the best results in term of heat exchanger performance regardless of its overall dimensions. The software tool is able to split the exchanger into sub-domains having homogeneous boundary conditions and then simulates the performance, both on the cold and hot side, in terms of the WHTC (Wall Heat Transfer Coefficient) and pressure drop, using CFD (Computational fluid dynamics) analysis. The basic idea is to simulate the entire radiator using sub-domains, considered as a combination of elements with series and parallel layout, as a function of the regions to be simulated.

The chapter is organized as follows. Section 13.2 presents the state of the art regarding the ability to develop a nanostructured coating able to change the fluid surface interaction, specifically to reach a contact angle greater than $110^{\circ} \mathrm{C}$. Section 13.3 proposes the overall approach to functionalize the whole heat exchanger without modifying the actual construction methodology. Section 13.4 presents the developed methodologies, tools, and prototypes. The testing and analysis of thermomechanical and corrosion analysis of functional layer is reported in Sect. 13.5. Finally, the conclusions are drawn in Sect. 13.6.

\subsection{State of the Art}

Although the heat exchangers are widely used both in mobile and fixed applications, to the best of our knowledge there are few examples of scientific works focused to the same approach proposed in this paper. The effect of contact angle (or surface 
wettability) on the convective heat transfer coefficient has been studied and a correlation between the pressure drop reduction and heat transfer coefficient has been found considering a hydrophilic surface [2].

In a steam condensation application, the use of a hydrophobic coating has improved the overall heat coefficient of more than 10 times [3]. In air conditioning applications, the pressure drop and the heat transfer have been studied considering a hydrophilic coating and a new correlation between heat, mass and momentum transfer has been proposed to describe the obtained results [4]. Furthermore, the use of a hydrophilic coating has enhanced the heat transfer performance and has reduced the pressure drop in a dehumidifying application [5]. The coating ability to promote fluid motion after the application of external forces was studied in the laminar field of motion [6] and in turbulent conditions [7, 8]. A relation between slip length and contact angle was studied in [9].

Wettability is the ability of a liquid to maintain contact with a solid surface. The wettability of the surface has a great influence on heat exchange, because it influences the type of motion that is established between surface and fluid. The impact of wettability effect on heat transfer was studied in [10]. The effect of contact angle (or surface wettability) on the convective heat transfer coefficient in microchannels was studied in [11], while a correlation between the contact angle and the wetting properties is proposed in [12]. In none of the previous studies, however, the possible connection between the reduction of the friction between the fluid and the surface, by means of the nanostructured coating, and the increase in the heat exchange performance was investigated. About the oleophobic performance obtained using the technology proposed in this paper, the main literature can be found in [1, 13-17].

\subsection{Problem Statement and Proposed Approach}

Cross-flow heat exchangers are widely used in automotive and earthmoving machinery applications because they can transfer a great quantity of thermal power in a relative small volume. The need to cool process fluids is always present and becomes critical when there is the need to concentrate a big amount of power in increasingly small dimensions. This is the case, for example, of new hybrid solutions, where to the thermal power generated by the ICE is added the thermal power developed by the driveline and the electric motor. This work is based on the hypothesis that, if heat transfer coefficient increases and friction power losses do not increase too much or even decrease, then it is then possible to transfer the same power by smaller dimensions or to transfer more thermal power by the same overall dimensions. The problem was addressed through five phases.

The first part of the work was dedicated to reduce the wettability of the surface thanks to the design and synthesis of coatings of various types, both organic and hybrid (organic-inorganic). In particular, we focused on the morphology of the nanostructure and on the surface chemistry that both have to be controlled and modulated (Sect. 13.4.1). In this context, the synthesis of ceramic oxides nanoparticles $\left(\mathrm{Al}_{2} \mathrm{O}_{3}\right.$, 
$\mathrm{ZrO}_{2}$, etc.) was studied to form a stable colloids or nanosuspensions in different media (i.e. alcohols or water). In this phase it was mandatory to have a high control degree on phases, particle size and composition. Also specific synthetic approaches were developed (i.e. sol-gel), involving particle nucleation directly from precursors present into the fluid, in the meantime avoiding particle precipitation and ensuring a better control over physical variables of suspensions.

The second phase was the adaptation of laboratory deposition techniques to the specific production process followed to make the brazed heat exchanger (Sect. 13.4.2). In this context, coating deposition by simple immersion techniques, such as dip-coating or spin-coating in controlled conditions, revealed to be suitable to produce homogeneous functional surfaces (turbolators), to easily control the layer thickness in the order of nanometers and to promote the formation of micro- and nanostructures. The main problem is related to the fact that the turbolators could be easily functionalized using the dip-coating, but they lost their superhydrophobic/oleophobic performance after the brazing phase, necessary to assembly turbolators and fins in order to produce a complete heat exchanger. For this reason other production techniques (e.g. pumping, suction) were experimented with the aim to investigate which of them could interfere as less as possible with the currently used production technique.

The third phase was the development of a software tool able to simulate the heat exchanger, considering the different possible combinations of turbolators and fins surfaces (Sect. 13.4.3). The heat exchanger was decomposed in main portions in which the flow has some peculiar characteristics (mainly from the point of view of boundary conditions applied). The final aim is to have a customized, yet flexible, tool able to predict the heat exchanger performance under different environmental conditions and geometry dimensions, considering not only the possibility to optimize the radiator by the fin geometry but also using the surface functionalization.

The assessment of functional performance of the obtained samples is the fourth phase of the work (Sect. 13.4.4). The setup of new measurement stations, in order to have practical estimates of the behaviour of different surface coating, was also taken into consideration during this part of the work. For instance, a prototype with reduced dimension was used to monitor the pressure drop and the exchanged power considering different nano-coating functionalized surface. The reasons grounding the choice of the test cycles, foreseen for the functional performance tests, derive from the experience gained in functional characterization of the components at the experimental stage and from the investigation of the relevant laboratory tests required by the applicable international standards. A key factor at this stage was the assessment of changes or damages to the microstructure of the functionalized layers after the test cycles.

The fifth and final phase was dedicated to the verification of new coating ability, in the expected operative conditions, to assure the efficiency improvement (Sect. 13.5). A complete tribological, corrosion and mechanical characterization of functional layers was performed. 


\subsection{Developed Technologies, Methodologies and Tools}

\subsubsection{Development of Functional Layer}

Super-hydrophobicity can be achieved, as exposed in the work by Bonanno et al. [1], by inducing a flower-like structure on a micro or nano-scale so that liquid droplets are not able to adhere to the surface because of air entrapped among the surface roughness. Attempting to repeat the Cassie-Baxter model in practice the target was to obtain a structure like the one in Fig. 13.1.

A super-hydrophobic or super-hydrophilic behaviour of the liquid droplets in contact to the surfaces in question can be obtained by changing a phase in the process:

- Super-hydrophilic behaviour

- $\mathrm{Al}_{2} \mathrm{O}_{3}$ nanoparticles sol deposition

- Heat treating

- Super-hydrophobic behaviour

- $\mathrm{Al}_{2} \mathrm{O}_{3}$ nanoparticles sol deposition (inorganic component)

- Heat treating

- Fluoridation with fluoroalkilsylane (FAS_-organic component) F8263.

A lubricant film can be used in a porous solid [18] to convey better mechanical resistance to the coating layer, high pressure resistance, self-healing, sand low friction. If the lubricant is immiscible, then the interface between the solid and the

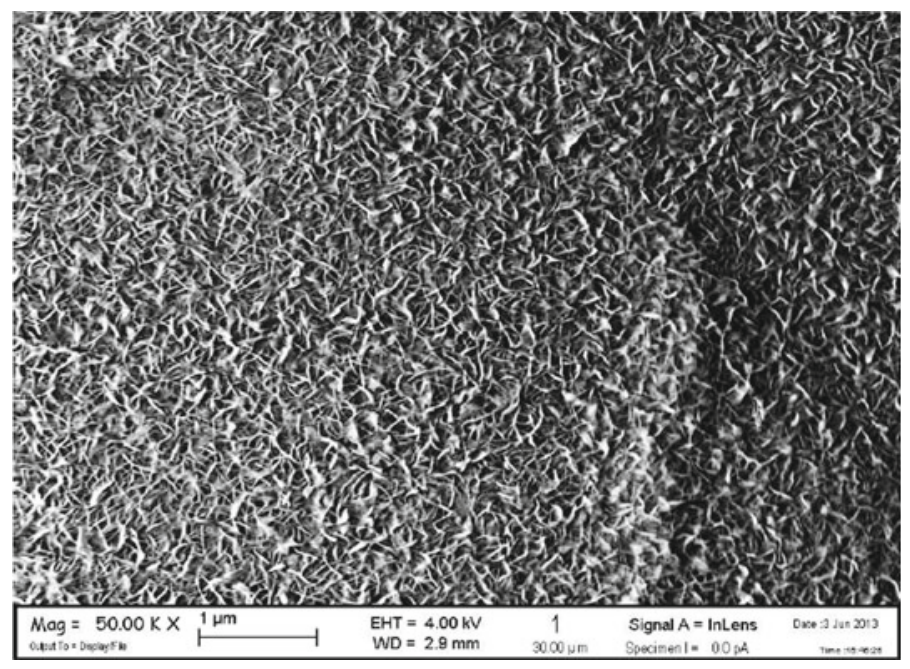

Fig. 13.1 SEM image of a Cassie-Baxter structure 
immiscible liquid is no more solid but liquid, meaning that the lubricant interposed between solid and liquid reduces the friction.

\subsubsection{Deposition Techniques}

A surface must be optimised to keep repellency stable over time. In fact, keeping the free energy of the solid/lubricant/liquid system as low as possible, it is possible to make the liquid reside on the surface of the lubricant without replacing it, thus eliminating the fixing points and obtaining extremely low sliding angles (super-repellent surfaces). This is true also for liquids with very low surface tensions [19]. A qualitative analysis showed the formation of the pinning effect, therefore the components were further functionalized with fluoridated lubricant FC-43 in order to obtain a stable repellency. The functionalization of singular components of a heat exchanger implicates a following bonding with further heat treatments that could damage the coating, and so threaten the relative hydrophobic effect. The general coating technique is the same described in the work by Bonanno et al. [1].

Three different coating techniques were developed and tested in this work:

- Functionalization by emptying. The functionalization by dip-coating (immersion in the solution) implies a strict dependence of the sol container on the heat exchanger dimensions. Besides the volume of sol to be produced must be sometimes much greater than the volume to be filled in the heat exchanger. The emptying method works taking advantage of the same principle as the dip-coating one, namely the relative motion between solid surface and coating liquid. In this case liquid moves to the solid which is steady whereas by dip-coating the solid moves and liquid is steady.

- Emptying by suction. This method consists in sucking the inner liquid, previously filled in the heat exchanger, using a controlled volume variation container like a syringe. Since the optimal liquid evacuation velocity is $2 \mathrm{~mm} / \mathrm{s}$ for both alumina suspension solution and FAS solution, an appropriate piston velocity must be assessed. This method presents the non-negligible advantage of using the exact volume of liquid necessary to fill the heat exchanger, furthermore, since both nanoparticles solution and FAS can be used more than once to coat the solid surface, several heat exchangers can be treated with the same solutions.

- Emptying by pumping. This method is based on emptying the treated heat exchanger by pumping the chemical solutions out of it by using a peristaltic pump which is volumetric (flow rate can be easily controlled by varying rotational speed) and suitable for low flow rate values $(0-100 \mathrm{ml} / \mathrm{min})$. The pump, activated by the electrical supply, sucks the solution from the heat exchanger and sends it to the bottle that works as a recovery container. After having emptied the heat exchanger the solution can be used again in another one. 
Fig. 13.2 Heat exchanger sub-domains

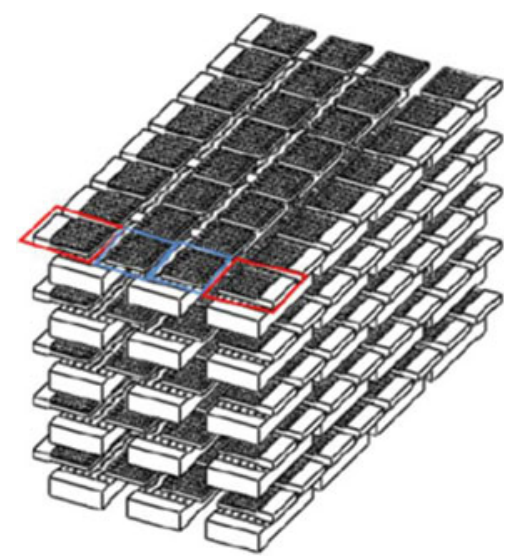

\subsubsection{Simulation of Heat Exchanger Performance}

As previously described, a dedicated software tool was developed to simulate the heat exchanger performance. By positioning on the $\mathrm{XZ}$ plane, the heat exchanger can be divided into a number of basic elements, which have certain geometric characteristics and fluid dynamics features. In particular, it can be distinguished an entrance area, an inner section and an output section of the cooling fluid. The same can be said for the hot fluid. Preliminary analyses have highlighted a substantial independence of the results from the direction of the fluid: heat transfer coefficients and pressure drop were slightly affected by the direction in which the transition plenum-interstices takes place. This consideration leads to match subdomains that present the same geometric properties regardless of the fluid dynamic condition in the subdomain. The result was to group the nine possible subdomains into four classes, in this way, only four subdomains have been analysed as representative from each class. Summarizing, the adopted methodology does not simulate the coupling of one or more rows of hot side fins with one or more cold side fins. Rather a small element of every single fin was analysed, by imposing on the single domain the boundary conditions that most likely will occur during operation. Then, through a revision of the results that is performed by means of a spreadsheet, the subdomains are reconstructed in a virtual exchanger so as to have the characteristic of the global heat exchanger. The heat exchanger is thermo-fluid-dynamically reconstructed (Fig. 13.2) by spacing layers (in parallel) consisting of an element of Type 2 (shown in red) input, which has $n$ elements in series Type 5 (highlighted in blue) and then conclude with an element of Type 2 output. In this way, the types of simulation domains are cut without significantly reducing the accuracy of the entire analysis. Initially, it was assumed that the size of the element could have an influence on the transfer coefficient due to the actual distribution of temperature on the wall of the fins. However, by performing a preliminary analysis on the influence of the size of the computational domain on the value of the heat transfer coefficient, there was a substantial independence from such a value. 
Table 13.1 Simulation conditions

\begin{tabular}{l|l|l|l|l}
\hline Fluid & $\begin{array}{l}\text { Tested } \\
\text { geometries }\end{array}$ & $\begin{array}{l}\text { Temperatures } \\
\left({ }^{\circ} \mathrm{C}\right)\end{array}$ & Subdomains & Velocities $(\mathrm{m} / \mathrm{s})$ \\
\hline Air & $\begin{array}{l}\text { A0, A1, A2, A3, } \\
\text { A4 }\end{array}$ & $20-40-60$ & Type 2-Type 5 & $2-4-6$ \\
\hline Water-glycol & P0-P2 & $60-80-120$ & Type 2-Type 5 & $0.2-0.4-0.6$ \\
\hline Oil & P0-P2 & $60-80-120$ & Type 2-Type 5 & $0.2-0.4-0.6$ \\
\hline Hot air & P1-P3 & $120-160-200$ & Type 2-Type 5 & $4-6-8$ \\
\hline
\end{tabular}

For each designed geometry, we have identified two types of domain:

- Type 2, characterized by the presence of the inlet plenum that is used to simulate the input section;

- Type 5, in which the plenum is absent because it represents the internal geometry of the heat exchanger.

A total amount of 5 geometries for fins (A0, A1, A2, A3, A4), 2 geometries for water-glycol and oil channels (P0 and P2) and 2 geometries for the air channels (P1 and P3) were analysed to assess the specific heat transfer coefficient and pressure drop. The simulations performed were 180, as reported in Table 13.1.

\subsubsection{Test Rig and Prototypes}

During the work several prototypes were realized and a dedicated test rig was built to properly test them. The test rig is shown in Fig. 13.3 and is composed of a service pipeline that is connected to a proportional valve, i.e. a gate valve controlling the flow rate through the heat exchanger. Before the beginning of the tests, a heater controls the temperature of the inlet oil by heating the whole mass of oil contained in the tank, so that the oil has a high heat capacity to keep at a constant temperature during the tests. The air flow (the cold fluid) is driven by a fan, actuated by a hydraulic motor, whose suction side is connected to the heat exchanger by a divergent duct. The oil temperatures (inlet and outlet), the oil flow, the air temperature, the oil and air pressures were all collected by a dedicated acquisition software, in order to have all the measured values coming from different transducers. In particular, two flow meters were installed to measure a wide range of volume flow rate: one has a full scale of $10 \mathrm{l} / \mathrm{min}$ and the other of $300 \mathrm{l} / \mathrm{min}$ that can be activated separately by ball valves placed upstream them.

All the measures were printed in a text file that can be imported into a postprocessing software to examine and derive other physical quantities not directly measured. A control panel of the acquisition software was developed from the ground up (both hardware and software) and used to monitor the working conditions of the test rig. 


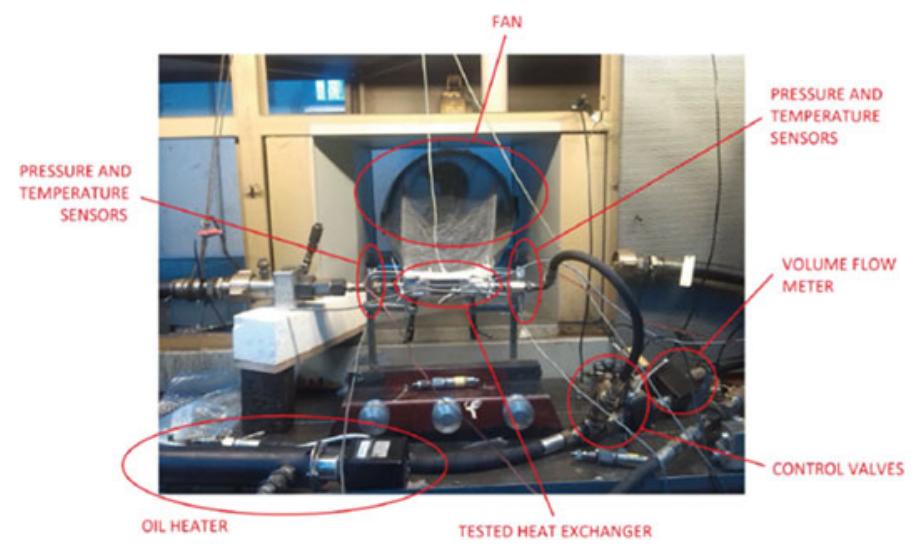

Fig. 13.3 Test rig for heat exchanger prototypes

(a)

(b)

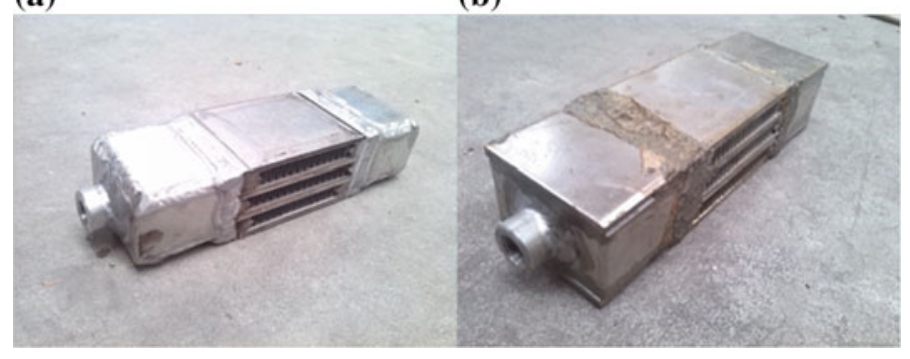

Fig. 13.4 Type $A$ heat exchanger $\mathbf{a}$ standard and $\mathbf{b}$ functionalized (right)

The first set of prototypes was developed by using the brazing technology to assemble the fin packs (Fig. 13.4) at about $600{ }^{\circ} \mathrm{C}$, temperature at which the nanostructured coating would be irreparably damaged. To avoid this, the samples were first assembled and brazed, and then coated, according to one of the technologies presented in Sect. 13.4.

Four different set of cross flow heat exchangers were realized as previously presented and tested:

- Type A: $63 \mathrm{~mm}$ by $100 \mathrm{~mm}$ by $46 \mathrm{~mm}$;

- Type B: $94 \mathrm{~mm}$ by $93 \mathrm{~mm}$ by $200 \mathrm{~mm}$;

- Type $C: 160 \mathrm{~mm}$ by $160 \mathrm{~mm}$ by $45 \mathrm{~mm}$;

- Bonded: $63 \mathrm{~mm}$ by $100 \mathrm{~mm}$ by $46 \mathrm{~mm}$.

The choice of testing three different shapes and dimensions of heat exchangers is justified by the necessity to verify if scale effect would have amplified their performance differences.

In the Type $A$ the lateral bowls were glued after the functionalization (by empting) of the fins pack as showed in Fig. 13.4 on the right. In the Types $B$ and $C$ the lateral 


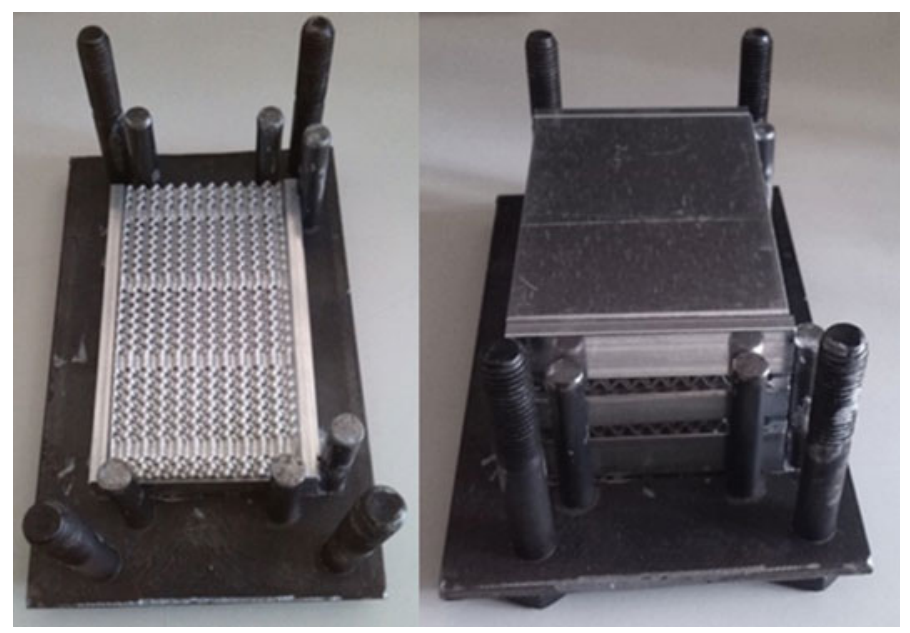

Fig. 13.5 Bonded heat exchanger

bowls were pre-assembled and the functionalization was obtained by pumping or by suction.

Due to the fact that the heat exchangers fins pack are always pre-assembled, it was impossible to evaluate if the coating process worked correctly, deposing and structuring the correct nano-structured superhydrophobic and oleophobic layer. A completely different set of prototypes were developed to solve this problem; these were assembled by bonding (Fig. 13.5). In this case the fins were singularly coated and the assembled together by bonding. All the prototypes showed until now (Type A, Type B, Type $C$ and Bonded) were tested using oil, which is the fluid normally used with this type of heat exchangers.

Finally, a fifth set of prototypes (Fig. 13.6) was prepared in order to evaluate the performance of a completely flat surface and using water as working fluid. This last set was developed to investigate the theoretical hypothesis for which the greater is the contact angle the lower is the friction between the fluid and the surface [20-22].

Because the nanostructured coating gives the best performance, in terms of contact angle as well as contact angle hysteresis and energetic interaction between fluid and surface, with water, we decided to develop a completely dedicated experimental set up and test. The testing rig works in a closed loop, when the prototype is selected, the water previously heated flows into the prototype heat exchanger and then returns to the pump. It is also possible to select the coated or the non-coated channel, because they are in parallel. This last test rig was used only with the channel prototype, whereas the test rig shown in Fig. 13.2 was used with all other prototypes tested using oil as working fluid. 


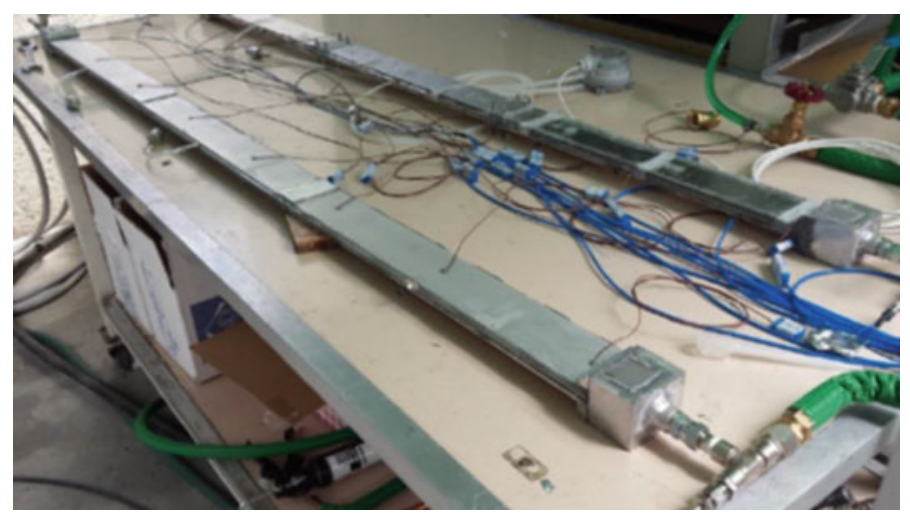

Fig. 13.6 Channel prototype

\subsection{Testing and Validation of Results}

Wettability of the samples treated with the techniques described in the previous section were measured using diiodomethane $\left(\mathrm{CH}_{2} \mathrm{I}_{2}\right.$ with a surface tension of 50.8 $\mathrm{mN} / \mathrm{m}$ ) because of the impossibility to measure the water contact angle due to a complete water proofing of the surface of heat exchanger fins (Fig. 13.7). The results showed a contact angle of $133.1^{\circ} \pm 7.1^{\circ}$ using the hybrid methodology and $123.8^{\circ} \pm 6.6^{\circ}$ using the lubricant. It can be noticed the good hydrophobicity achieved with the hybrid method against the lubricant one on the liquid side fins. It was also tested the possibility to achieve a direct functionalization through fluoridation only (agent $\mathrm{F}$ 8263). The assessment was done through water contact angle (WCA), $\mathrm{CH}_{2} \mathrm{I}_{2}$ contact angle, and surface energy (SE) measurement. The WCA was $136.2^{\circ} \pm 34.7^{\circ}$, the $\mathrm{CH}_{2} \mathrm{I}_{2}$ contact angle was $70.9^{\circ} \pm 10.9^{\circ}$ whereas the $\mathrm{SE}$ was $7.28 \pm 23.91 \mathrm{mN} / \mathrm{m}$. From the results obtained, it comes out the nano-structuring necessity to achieve super-hydrophobicity.

The heat resistance assessment of the coated layers was performed at three different temperatures:

- Heating at $200{ }^{\circ} \mathrm{C}$ for $2 \mathrm{~h}$-the results showed that the superhydrophobicity/oleophobicity is maintained;

- Heating at $300{ }^{\circ} \mathrm{C}$ for $2 \mathrm{~h}$-still hydrophobic surfaces (spherical droplets) but lower slipping;

- Heating at $400{ }^{\circ} \mathrm{C}$ for $2 \mathrm{~h}$-destruction of the organic component of the coating, with subsequent super-hydrophilicity.

The results confirm that the brazing production methodology currently employed is not compatible with the nanostructured superhydrophobic layer.

The test rig (see Sect. 13.4.4) was designed to supply prototype heat exchangers with suitable thermal and hydraulic power to be dissipated. After measuring the three physical quantities (volume flow rate, static temperature and static pressure) thanks to 
(a)

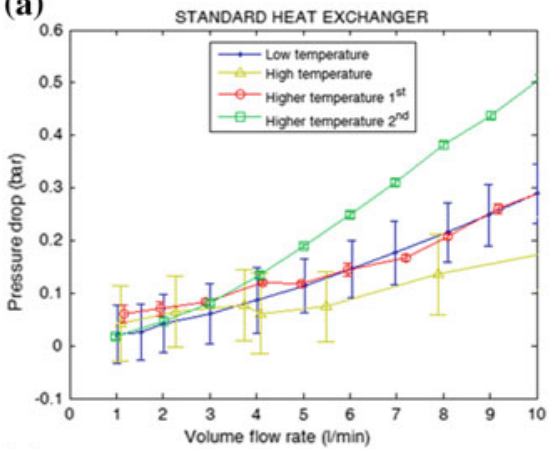

(c)

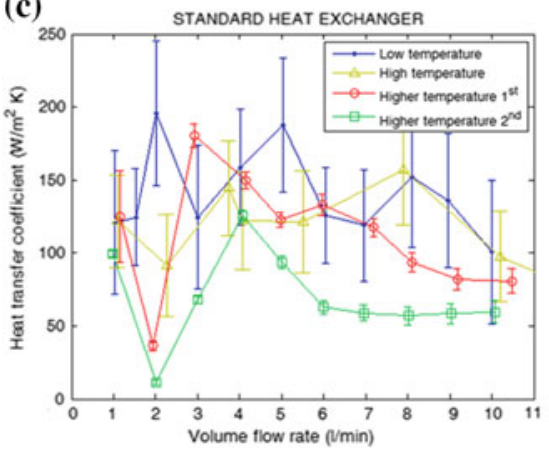

(b)

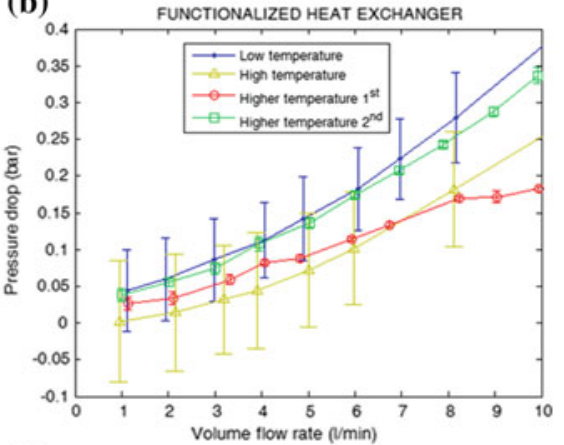

(d)

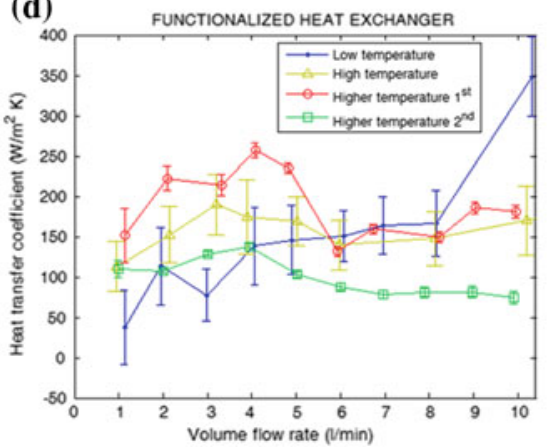

Fig. 13.7 Experimental results: a standard heat exchanger pressure drop at different temperatures; b functionalized heat exchanger pressure drop at different temperatures; $\mathbf{c}$ standard heat exchanger heat transfer coefficient at different temperatures; $\mathbf{d}$ functionalized heat exchanger heat transfer coefficient at different temperatures

the sensors in the test rig and knowing the thermo-physical properties of the process fluid (hydraulic oil), it is possible to extrapolate the overall Darcy viscous friction factor $f$ according to Eq. (13.1) and the overall heat transfer coefficient $U$ according to Eq. (13.2).

$$
\begin{gathered}
f=\frac{2 * S_{f}^{2} * \Delta p_{m}}{\rho(t) * Q^{2}} \\
U=\frac{\rho(t) * Q * c_{p} * \Delta T_{m}}{S_{h} * \Delta T_{m} * F}
\end{gathered}
$$

$S_{f}$ is the flow through surface at the inlet of the finned part of the heat exchanger, $\Delta p_{m}$ is the static pressure difference measured upstream and downstream the heat exchanger, $\rho(t)$ is the mass density of the fluid as a function of the instant temperature of the fluid, $Q$ is the volume flow rate of the fluid, $c_{p}$ is the specific heat capacity at constant pressure of the fluid, $\Delta T_{m}$ is the measured temperature difference between upstream and downstream the heat exchanger, $S_{h}$ is the heat transfer surface of 
the finned part of the heat exchanger, $\Delta T_{m l}$ is the logarithmic mean temperature difference, $F$ is a correction factor [23] depending on the shape of the heat exchanger and the way the fluids interact each other thermally and dynamically.

Four tests were carried out in two periods (or stages):

1. Test of Type $A$ heat exchangers at three different inlet oil temperature conditions: $40,65,70{ }^{\circ} \mathrm{C}$ (two tests have been performed at $70{ }^{\circ} \mathrm{C}$ ). For each working condition, volume flow rate was varied between 1 and $10 \mathrm{l} / \mathrm{min}$ with a step of $1 \mathrm{l} / \mathrm{min}$.

2. Test of Type A, Type B, Type $C$ and Bonded in the updated test rig at three different inlet oil temperature conditions: $50,70,85^{\circ} \mathrm{C}$.

The second stage corresponds to an evolution of the first one inasmuch the test rig has been improved and more attention paid to the data acquisition system. The geometrical correction factor $F$ can be considered equal to one with good accuracy in each working condition.

The idea of a channel (basically a rectangular cross section pipe as showed in Fig. 13.6 has been conceived to study the behaviour of water in contact to straight walls that interact with liquid only through viscous friction.

The next subsections present the results of the main experiments.

\subsubsection{Type A Heat Exchanger}

Figure 13.7a and b show how differences in pressure losses behaviour occur as inlet oil temperature values change. At $40{ }^{\circ} \mathrm{C}$ the pressure drop distribution seems to be regular and relative to a smooth curve in the standard heat exchanger and in the functionalized one; at 65 and $70{ }^{\circ} \mathrm{C}$ the standard heat exchanger pressure losses curves present regions of flow instability whereas the functionalized curves exhibit it only at $70{ }^{\circ} \mathrm{C}$ inlet oil temperature. This behaviour could be explained considering laminar to turbulent flow transitions. Heat transfer coefficient is characterized by a great measurement uncertainty for volume flow rate values less than $71 / \mathrm{min}$ so it is not possible to extrapolate a precise trend in that range. After $71 / \mathrm{min}$ the trend is to reach an asymptote which in the functionalized heat exchanger seems to be greater of about $50 \%$ than in the standard one. By observing the curves in Fig. 13.7c and d it can be said that heat transfer coefficient values, for volume flow rate values less than $7 \mathrm{l} / \mathrm{min}$, are basically diffused nearby a mean value of $116.46 \pm 38.73\left(\mathrm{~W} / \mathrm{m}^{2} \mathrm{~K}\right)$ for standard heat exchanger and $176.47 \pm 59.45\left(\mathrm{~W} / \mathrm{m}^{2} \mathrm{~K}\right)$ for the functionalized one.

\subsubsection{Type B, Type C and Bonded Heat Exchangers}

Contrary to Type A, no remarkable improvements of the functionalized heat exchanger on the standard one have been recorded, both in terms of thermal and 
Table 13.2 Channel test results (Test 1)

\begin{tabular}{l|l|l|l|l}
\hline \multirow{2}{*}{ Flow rate (1/min) } & \multicolumn{2}{|l|}{$\begin{array}{l}\text { Standard channel exchanged } \\
\text { thermal power }(\mathrm{W})\end{array}$} & \multicolumn{2}{l}{$\begin{array}{l}\text { Functionalized channel exchanged } \\
\text { thermal power }(\mathrm{W})\end{array}$} \\
\cline { 2 - 5 } & Mean & Std. Dev. & Mean & Std. Dev. \\
\hline 1 & 127 & \pm 5 & 192 & \pm 5 \\
\hline 1.6 & 165 & \pm 4 & 212 & \pm 5 \\
\hline 3.1 & 178 & \pm 4 & 231 & \pm 11 \\
\hline
\end{tabular}

pressure loss performance. Probably the results are related to the different coating technology that was used.

\subsubsection{Test on Channel}

The tests on channel were performed using water instead of oil. Between the first test and the others some weeks passed, due to a temporary unavailability of test rig. During this stand-by period, the channel remained full of water. The results obtained in the first test could be summarised as reported in Table 13.2.

In none of subsequent tests similar results were obtained. The thermal power exchanged with functionalized channel was quite similar to those obtained using standard channel. The reason of this behaviour could be explained thanks the corrosion test results. Corrosion behaviour of AA1050 aluminium alloy samples with super-hydrophobic coating has been assessed during salt fog and water/ethylene glycol mixture exposure at $80^{\circ} \mathrm{C}$, both in presence and in absence of chloride ions.

The survey evidenced that the super-hydrophobic layer is able to offer just a partial protection to the metallic sublayer when exposed to an aggressive environment like the salt fog one. Even after short exposure time, the layer loses its super-hydrophobic features because of local corrosion process arise on the layer defects that evolve towards deep penetrating forms. The same behaviour was noted using a less aggressive environment, like water/ethylene glycol mixture exposure at $80^{\circ} \mathrm{C}$, in presence of $200 \mathrm{ppm}$ of chloride ions. Therefore, due to the fact that the tests with channels were performed using normal potable water, the different behaviour noted could be explained with a degradation of super-hydrophobic layer due to corrosion.

\subsubsection{Customized Software to Design Tailored Heat Exchanger}

We performed 180 CFD simulation to characterize the different fins geometry (both for oil, water and air), considering different temperatures and flow velocities. Once 
(a)

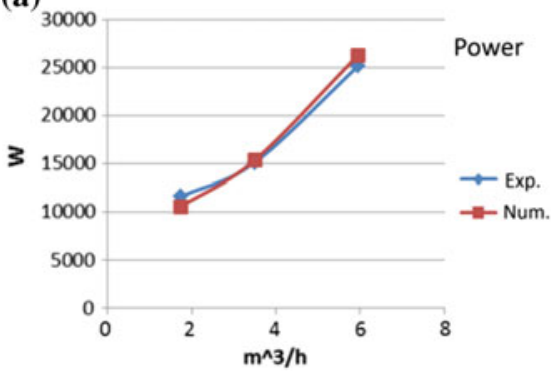

(b)

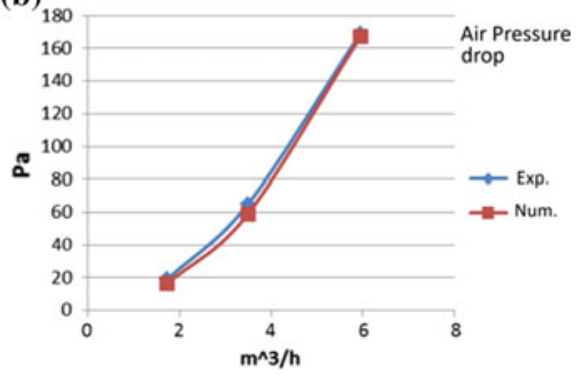

Fig. 13.8 Comparison between numerical (red square) and experimental (blue diamond) results. a Exchanged power; $\mathbf{b}$ Air pressure drop

the generic exchanger is reconstructed as a set of Type 2 and Type 5 sub-domains, it is necessary to use the results of the fluid dynamic analyses, in order to define the behaviour of each sub-domain in terms of WHTC (wall heat transfer coefficient) and pressure losses. The obtained data were interpolated, using cubic splines, to describe the subdomain behaviour in working conditions different from those simulated. This calculation was repeated for every sub-domain (Type 2 and Type 5) of the exchanger as a function of the mean passage velocity and temperature. An identical approach is applied to determinate the pressure losses. The same procedure was also utilized for generating the curves of the density variation of the generic fluid that flows into the generic sub-domain as a function of the temperature. The results obtained using this approach show a good agreement between the calculated and tested performance, as showed in the Fig. 13.8. The mean error between the numerical and experimental results is $\pm 6 \%$ for the exchanged power (Fig. 13.8a) and 3\% for the pressure drop (Fig. 13.8b).

\subsection{Conclusions and Future Research}

This work investigated the potential of surface nano-coating of heat exchanger in order to improve the thermal efficiency of the component. We have designed and synthesized a functional layer, obtaining a good granulometric distribution of the suspension. We have demonstrated the feasibility of the coating processes and the adaptability of deposition techniques to the cross flow heat exchanger fins. Using dipcoating technique we were able to coat many finned surfaces. The results showed a contact angle of $133.1^{\circ} \pm 7.1^{\circ}$ using the hybrid methodology and $123.8^{\circ} \pm 6.6^{\circ}$ using the lubricant. It can be noticed the good hydrophobicity achieved with the hybrid method against the lubricant one on the liquid side fins. This means that one of the objectives of this project has been reached: to change completely the surface behaviour. Different coating methodologies were tested (pumping, empting, etc.) and none of them showed clearly the possibility to follow the actual production 
methodology (by brazing) of cross flow heat exchanger, which should be probably modified.

The influence of the new superhydrophobic and oleophobic surface on the heat exchanger behaviour was studied thanks to a dedicated test rig. The results show that, for the Type $A$ heat exchanger, the heat transfer coefficient values, for volume flow rate values less than $7 \mathrm{l} / \mathrm{min}$, are basically diffused nearby a mean value of $116.46 \pm 38.73\left(\mathrm{~W} / \mathrm{m}^{2} \mathrm{~K}\right)$ for standard heat exchanger and $176.47 \pm 59.45$ $\left(\mathrm{W} / \mathrm{m}^{2} \mathrm{~K}\right)$ for the functionalized one. The same results were not found in the other heat exchanger (Type B, Type $C$, Bonded) probably due to the different coating methodology used. A last test was performed using water instead of oil and considering a different heat exchanger geometry (channel). In this last test the first set of results obtained show a good improvement of heat exchange coefficient $(\approx+20 \%)$, but the test performed after some weeks on the same component did not confirm this trend. The results become clearer after the corrosion test, were the survey evidenced that the super-hydrophobic layer is able to offer just a partial protection to the metallic sublayer when exposed to an aggressive environment like the salt fog one. Even after short exposure time, the layer loses its super-hydrophobic features because of local corrosion process arise on the layer defects that evolve towards deep penetrating forms. Finally, a dedicated modular software was developed. The results obtained comparing the experimental results with the numerical one show good agreement considering both the heat exchanger power and pressure drop. Further results related to this work are presented in the papers [24-30].

Finally, the exploitation of the scientific results led to the submission and approval of a research project titled HEAT (nano coated Heat ExchAnger with improved Thermal performances) funded under the call POR-FESR 2014-2020 of Regione Emilia Romagna. This project is coordinated by ISTEC-CNR in cooperation with FIRA spa and COMEX EUROPE srl.

Acknowledgements This work has been funded by the Italian Ministry of Education, Universities and Research (MIUR) under the Flagship Project "Factories of the Future - Italy" (Progetto Bandiera "La Fabbrica del Futuro") [31], Sottoprogetto 2, research projects "Customized Heat exchanger with Improved Nano-coated surface for earth moving machines Applications" (CHINA) and "Thermally Improved Heat Exchangers prototypes with Superhydrophobic Internal Surfaces: new assembly procedures and materials" (THESIS).

The authors express their gratitude to the following researcher, for the precious and effective collaboration, without which all this work would not be possible: Eng. Giuseppe Rizzo, Eng. Giorgio Paolo Massarotti, Eng. Luca Pastorello, Dr. Maria Giulia Faga, Dr. Giovanna Gautier, Dr. Federico Veronesi, Dr. Magda Blosi, Dr. Aurora Caldarelli, Dr. Giulio Boveri, Mrs. Guia Guarini.

The authors would like to thank for his indispensable technical and methodological contribution, FIRA S.p.A., which developed the heat exchangers and gave the necessary support to perform all the tests and to develop the different prototypes.

This work would not have been possible without the foresight of Prof. Roberto Paoluzzi, in memory of whom this paper was written. 


\section{References}

1. Bonanno A, Raimondo MR, Zapperi S (2019) Surface nano-structured coating for improved performance of axial piston pumps. In: Tolio T, Copani G, Terkaj W (eds) Factories of the future. Springer

2. Rosengarten G, Cooper-White J, Metcalfe G (2006) Experimental and analytical study of the effect of contact angle on liquid convective heat transfer in microchannels. Int $\mathbf{J}$ Heat Mass Trans 49(21)

3. Lara JR, Holtzapple MT (2011) Experimental investigation of dropwise condensation on hydrophobic heat exchanger. Part II: effect of coatings and surface geometry. Desalination 280:363-369

4. Sheng Y, Quing-Ding W (2006) Experimental study on physical mechanism of drag reduction of hydrophobic materials in laminar flow. Chin Phys Lett 23(6):1634

5. Xiaokui M, Ding G, Zhang Y, Wang K (2009) Airside characteristics of heat, mass transfer and pressure drop for heat exchangers of tube-in hydrophilic coating wavy fin under dehumidifying conditions. Int J Heat Mass Transf 52:4358-4370

6. Jiaguo Y, Xiujian Z, Qingnan Z, Gao W (2001) Preparation and characterization of superhydrophilic porous TiO2 coating films. Mater Chem Phys 68:253-259

7. Rothstein PJ (2010) Slip on Superhydrophobic Surfaces. Annu Rev Fluid Mech 42:89-109. https://doi.org/10.1146/annurev-fluid-121108-145558

8. Martell MB, Rothstein JP, Perot JB (2010) An analysis of superhydrophobic turbulent drag reduction mechanisms using direct numerical simulation. Phys Fluids (22), 065102. American Institute of Physics, https://doi.org/10.1063/1.3432514

9. Bsushan B, Wang Y, Maali A (2009) Boundary slip study on hydrophilic, hydrophobic, and superhydrophobic surfaces with dynamic atomic force microscopy. Langmuir 25(14):8117-8121. https://doi.org/10.1021/la900612s

10. Choi C, Moohwan K (2011) Wettability effects on heat transfer, two phase flow, phase change and numerical modeling. Ahsan A (ed) InTech. https://doi.org/10.5772/19512

11. Rosengarten G, Cooper-White J, Metcalfe G (2010) Experimental and analytical study of the effect of contact angle on liquid convective heat transfer in microchannels. Int J Heat Mass Transf 49:4161-4170

12. Liu K, Yao X, Jiang L (2010) Recent development in bio-inspired special wettability. Chem Soc Rev 39:3240-3255. https://doi.org/10.1039/b917112f

13. Tuteja A, Choi W, Mabry JM, McKinley GH, Cohen RE (2007) Designing super-oleophobic surfaces. Science 318:1618-1622. https://doi.org/10.1126/science.1148326

14. Bhushan B (2011) Biomimetic inspired surfaces for drag reduction and oleophobicity/philicity. Beilstein J Nanotech 2:66-68. https://doi.org/10.3762/bjnano.2.9

15. Rimondo M, Blosi M, Bezzi F, Mingazzini C (2011) Metodo per il Trattamento di Superfici Ceramiche per Conferire alle Stesse una Elevata Idrofobicità e Oleofobicità. Patent RM2011A000104

16. Raimondo M, Blosi M, Bezzi F, Mingazzini C (2012) Metodo di Trattamento di Superfici Metalliche per Conferire alle Stesse una Elevata Idrofobicità ed Oleofobicità. Patent RM2012A000291

17. Raimondo M (2012) Making super-hydrophobic building materials: static and dynamic behavior of nanostructured surface. In: IV ICC4 international ceramic conference, Chicago (USA), July 14-19 2012

18. Wong TS, Kang SH, Tang SK, Smythe EJ, Hatton BD, Grinthal A, Aizenberg J (2011) Bioinspired self-repairing slippery surfaces with pressure-stable omniphobicity. Nature 477(7365):443-447. https://doi.org/10.1038/nature10447

19. Vogel N, Belisle R, Hatton B, Wong T, Aizenberg J (2013) Transparency and damage tolerance of patternable omniphobic lubricated surfaces based on inverse colloidal monolayers. Nat Commun 4:2176. https://doi.org/10.1038/ncomms3176

20. Ingebrigtsen T, Toxvaerd S (2007) Contact angles of Lennard-Jones liquids and droplets on planar surfaces. J Phys Chem C 111:8518 
21. Hong SD, Ha MY, Balachandar S (2009) Static and dynamic contact angles of water droplet on a solid surface using molecular dynamics simulation. J Coll Interf Sci 339:187

22. Park JY, Ha MY, Choi HJ, Hong SD, Yoon HS (2011) A study on the contact angles of a water droplet on smooth and rough solid surfaces. J Mech Sci Technol 25:323

23. Kakaç S, Liu H (1998) Heat exchangers selection, rating and thermal design. CRC Press LLC

24. Pastorello L, Bonanno A (2015) Application of Nano-structured coatings to heat transfer surface of heat exchangers. In: The fourteenth scandinavian international conference on fluid power, May 20-22, 2015, Tampere, Finland

25. Paoluzzi R, Bonanno A, Ferrari C, Martelli M (2014) Procedure for hydraulic oil heat exchanger performance improvement through integrated CFD analysis. Int J Fluid Power 15(3):169-180

26. Raimondo M, Blosi M, Caldarelli A, Guarini G, Veronesi F (2014) Wetting behavior and remarkable durability of amphiphobic aluminum alloys surfaces in a wide range of environmental conditions. Chem Eng J 258:101-109. https://doi.org/10.1016/j.cej.2014.07.076

27. Caldarelli A, Raimondo M, Veronesi F, Boveri G, Guarini G (2015) Sol-gel route for the building up of superhydrophobic nanostructured hybrid-coatings on copper surfaces. Surf Coat Technol 276:408-415. https://doi.org/10.1016/j.surfcoat.2015.06.037

28. Motta A, Cannelli O, Boccia A, Zanoni R, Raimondo M, Caldarelli A, Veronesi F (2015) A mechanistic explanation of the peculiar amphiphobic properties of hybrid organic-inorganic coatings by combining XPS characterization and DFT modeling. ACS Appl Mater Interfaces 7:19941-19947. https://doi.org/10.1021/acsami.5b04376

29. Malavasi Veronesi F, Caldarelli A, Zani M, Raimondo M, Marengo M (2016) Is a knowledge of surface topology and contact angles enough to define the drop impact outcome? Langmuir 32:6255-6262. https://doi.org/10.1021/acs.langmuir.6b01117

30. Raimondo M, Veronesi F, Boveri G, Guarini G, Motta A, Zanoni R (2017) Superhydrophobic properties induced by sol-gel routes on copper surfaces. Appl Surf Sci 422:1022-1029. https:// doi.org/10.1016/j.apsusc.2017.05.257

31. Terkaj W, Tolio T (2019) The Italian flagship project: factories of the future. In: Tolio T, Copani G, Terkaj W (eds) Factories of the future. Springer

Open Access This book is licensed under the terms of the Creative Commons Attribution 4.0 International License (http://creativecommons.org/licenses/by/4.0/), which permits use, sharing, adaptation, distribution and reproduction in any medium or format, as long as you give appropriate credit to the original author(s) and the source, provide a link to the Creative Commons licence and indicate if changes were made.

The images or other third party material in this book are included in the book's Creative Commons licence, unless indicated otherwise in a credit line to the material. If material is not included in the book's Creative Commons licence and your intended use is not permitted by statutory regulation or exceeds the permitted use, you will need to obtain permission directly from the copyright holder.

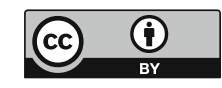

